\title{
VIDA, TRABALHO E VALOR NO SÉCULO XXI: desfazendo o nó ${ }^{1}$
}

\author{
Ursula Elin Huws *
}

\begin{abstract}
Costuma-se argumentar que a teoria do valor-trabalho de Marx não mais se aplica ao mundo contemporâneo, em que partes crescentes da população estão envolvidas em trabalho "imaterial" ou trabalho "digital". Este ensaio argumenta que essa teoria ainda é relevante, mas que, a fim de entender como ela pode ser aplicada ao trabalho imaterial e ao trabalho de modo mais geral, é necessário analisar criticamente os três principais componentes da teoria: a natureza particular de qualquer forma de trabalho, o valor que é criado por esse trabalho e os meios de subsistência do trabalhador. Essa análise nos permite não apenas distinguir entre "tempo de trabalho necessário" e mais-valia, mas também identificar o local de produção. Em um mundo em que novas atividades estão sendo constantemente trazidas para dentro da esfera das relações sociais capitalistas e novas mercadorias sendo produzidas, é importante identificar esses locais de produção e os trabalhadores que estão diretamente envolvidos na produção de mais-valia, porque são esses trabalhadores que têm o potencial, ao retirar seu consentimento, de se organizar de forma eficaz junto aos interesses comuns da classe trabalhadora global.

PALAVRAS-Chave: Teoria do valor trabalho. Trabalho imaterial. Mercadorização. Monetarização da internet. Trabalho. Trabalho digital. Trabalho produtivo e improdutivo.
\end{abstract}

Como o marxismo esteve continuadamente dentro ou fora de moda, dificilmente há um conceito marxista que, em algum momento, não tenha sido questionado como anacrônico à luz das transformações econômicas e políticas que ocorreram ao longo do último século e meio. A atual renovação do interesse nas ideias de Marx não é uma exceção. De fato, não é tarefa fácil aplicar conceitos teóricos desenvolvidos em meados do século XIX a um mundo onde o capitalismo penetrou em cada região e em cada aspecto da vida, onde o ritmo da mudança tecnológica é tão rápido, que processos de trabalho se tornam obsoletos meses após serem introduzidos, e onde a divisão do trabalho é tão intrincada que nenhum trabalhador individual tem alguma chance de apreendê-la em toda sua complexidade. Divisões entre trabalho manual e não manual são desfeitas e reconstituídas, fronteiras

* Doutora em Sociologia pela London Metropolitan University. Professora do Departamento de Business da Universidade de Hertfordshire.

Hatfield, AL10 9AB, UK.u.huws@herts.ac.uk

${ }^{1}$ Uma versão alterada deste ensaio foi publicada em Socialist Register, 2014, com o título "The Underpinnings of Class in the Digital Age: Living, Labour and Value”. Tradução: Sávio Cavalcante e Murillo van der Laan. entre produção, distribuição e consumo aos poucos se dissolvem e, enquanto alguns trabalhos remunerados se transformam em trabalhos não remunerados, novos empregos e novas atividades econômicas são geradas a partir de áreas da vida que foram tradicionalmente vistas como fora do escopo de qualquer mercado. No vai e vem da mercadorização, ${ }^{2} \mathrm{o}$ abstrato se torna concreto e o concreto, abstrato, lançando dúvidas sobre categorias conceituais que, a princípio, pareciam autoevidentes. Pode parecer que nós precisamos de novas definições dos conceitos mais básicos usados por Marx, inclusos os de "classe", "mercadoria" e "trabalho".

Uma ideia em voga, que tem atraído considerável apoio, especialmente entre os mais jovens, é a noção de que a ideia de classe trabalhadora definida por sua relação direta com a produção é antiquada. Segundo tais argumentos, como todos os aspectos da vida foram desenhados, de alguma forma, no âmbito do nexo capitalista do dinheiro,

2 N.T.: ao longo do texto, optamos pelo neologismo "mercadorização" para expressar o sentido do termo commodification utilizado pela autora. 
todos aqueles que não são, de fato, parte da classe capitalista devem ser considerados como parte de uma "multidão" indiferenciada que, na formulação de Hardt e Negri (2004), assume o lugar da classe trabalhadora; ou um "precariado" que, segundo Standing (2011), constitui uma nova classe em si e para si ao lado do proletariado tradicional. Standing não procura situar esse "precariado" com qualquer precisão em relação aos processos de produção capitalistas. Entretanto, muitos dos seguidores de Hardt e Negri têm se empenhado em tentativas detalhadas de fazê-lo em relação à "multidão". Duas questões em particular os têm confundido: que tipo de mercadoria está sendo produzido pelos membros dessa multidão quando ela se envolve em trabalho "imaterial”, "afetivo" (Hardt; Negri, 2004) ou "livre" (Terranova, 2000)? E como o valor produzido por esse trabalho reverterá ao capital?

Nesses debates, uma atenção particular tem sido dada ao valor criado online pelo trabalho virtual ou digital. No campo que tem se tornado conhecido como internet studies, houve recentemente debates acalorados sobre o trabalho $\operatorname{digital}^{3} \mathrm{e}$ como ele deveria ser conceituado. Esses debates têm abordado as fronteiras crescentemente difusas entre trabalho [labour] e jogo [play] (sintetizadas pelo termo playbor (Kücklich, 2005) e entre produção e consumo (prosumption ${ }^{4}$ e cocriação $0^{5}$ ); têm discutido a categoria problemática de trabalho li$\mathrm{vre}^{6}$ e questionado se tal trabalho, pago ou não pago, pode ser considerado como produtor de maisvalia e se ele é passível de ser explorado ou alienado. À exceção de Ross, poucos desses autores têm esboçado paralelos com outras formas de trabalho realizadas off-line. Porém, muitas das questões que eles levantam se aplicam muito mais ao trabalho

Ver, por exemplo: Andrejevic (2009), Arvidsson e Colleoni (2012), Banks e Humphreys (2008), Fuchs (2010), Fuchs (2012), Hesmondhalgh (2011), Ross (2012), Scholz (2012), Terranova (2012).

${ }^{4}$ Alvin Toffler cunhou esse termo em seu livro The Third Wave, de 1980, publicado pela Bantam Books. Desde então, tem sido usado por diversos outros escritores trabalhando nos marcos do marxismo, incluso Christian Fuchs e Ed Comer.

${ }^{5}$ A expressão é de Banks e Humphreys (2008), que usam um termo derivado de Prahalad e Ramaswamy (2000).

${ }^{6}$ Termo cunhado por Terranova em seu influente artigo publicado em 2000. sob o capitalismo. Esses debates, assim, fornecem um ponto de partida útil para investigar a própria teoria do valor trabalho e como (ou, alguém poderia se perguntar, mesmo se) ela pode ser empregada no contexto do século XXI.

Este ensaio sustenta que ainda é possível utilizar a teoria de Marx nas condições atuais para definir o que é, ou não é, uma mercadoria, para identificar o local de produção de tais mercadorias, sejam materiais ou imateriais, e para definir a classe trabalhadora global em relação a esses processos de produção. Para proceder de tal maneira, entretanto, é necessário reexaminar a teoria do valor trabalho em todas as suas dimensões. Eu concedo atenção particular aos trabalhos de natureza “digital” ou "virtual”, não apenas porque eles estão atualmente atraindo muita atenção, mas também porque o trabalho on-line é particularmente difícil de conceituar. Ele é, dessa forma, uma fonte fértil de casos exemplares a partir dos quais podem ser testadas hipóteses mais amplas. Se uma teoria pode ser aplicada nesse caso, então ela deveria ser aplicável de maneira geral. O objetivo de assim proceder é permitir um mapeamento mais geral da classe trabalhadora, ao longo de toda a economia, ao utilizar a teoria de forma mais ampla (como Marx o fez). Essa é uma tarefa importante, a meu ver, porque, sem uma clara noção dos trabalhadores que estão diretamente envolvidos na relação antagônica com o capital, o que caracteriza a produção de mercadorias, e sem identificar onde a produção está localizada, é impossível identificar estratégias que permitirão que o trabalho confronte o capital no local onde é possível exercer algum poder para moldar o futuro de acordo com seus próprios interesses.

A teoria do valor trabalho é o nó que está no centro da conceitualização de Marx do capitalismo como uma relação social. Ela une integralmente três coisas: a necessidade de subsistência dos trabalhadores, seu trabalho e a mais-valia expropriada dos resultados desse trabalho, sem a qual o capital não pode ser acumulado ou o capitalismo se perpetuar. A expropriação de trabalho é o ato de violência no centro dessa relação, e é o tempo 
de trabalho dos trabalhadores que constitui o âmago da luta dessa mesma relação, de maneira que um entendimento sobre como e sob quais circunstâncias essa expropriação se realiza é crucial para a compreensão tanto do capitalismo como um sistema quanto para o entendimento sobre que trabalhadores podem ser considerados como pertencentes à classe trabalhadora. O nó não pode ser desfeito: cada laço é essencial para manter o sistema unido. Não obstante, parece necessário examinálo, fio por fio, para então podermos apreender como ele se une, o que o contrai e o que permite que novos segmentos sejam emaranhados ou, para os que já existem, que eles fiquem entrelaçados de uma forma mais elaborada.

Na sua forma mais básica, o argumento é notavelmente simples: o trabalhador, obrigado a fazê-lo para sobreviver, trabalha um número dado de horas para o capitalista, produzindo certo valor como resultado. Parte desse valor é essencial para cobrir os custos de subsistência, e as horas trabalhadas para produzir esse valor ("tempo de trabalho necessário") são (usualmente) reembolsadas. O restante ("mais-valia") é apropriado pelo capitalista para distribuir como lucro e investir em novos meios de produção. Com base em um exame mais próximo, contudo, praticamente todo elemento dessa simples história se mostra aberto a questionamentos. O que, exatamente, é trabalho (labour)? E, mais particularmente, que trabalho é produtivo? Como a subsistência deve ser definida? Isso inclui apenas o que o trabalhador individual precisa para se manter, ou também inclui o que é requerido para o sustento de todo seu lar? Se não pudermos definir subsistência de forma precisa, como poderemos calcular o "tempo de trabalho necessário"? E, apenas porque todo valor, no interior do capitalismo, deriva, em última instância, dos resultados do trabalho humano empregado às matérias-primas da terra, isso significa que todo o valor que reverte ao capitalista individual é necessariamente mais-valia?

Os debates atuais em torno do trabalho digital tocam superficialmente algumas dessas questões e simplificam outras demasiadamente. Este ensaio não pretende reescrever toda a teoria de Marx. Em vez disso, tomará algumas das questões levantadas nesses debates sobre trabalho digital como ponto de partida para examinar os fatores que devem ser levados em conta em qualquer elaboração contemporânea da teoria de Marx. Isso será feito ao tentar desembaraçar os três fios - vida (ou subsistência), trabalho e valor -, de modo a categorizar seus componentes em separado, o que faremos em ordem inversa, refletindo as prioridades dos atuais debates nesse campo.

Esses conceitos são todos muito usados e difíceis de ser reempregados sem trazer conjuntamente uma carga grande de significados associados, intencionais ou não intencionais. Portanto talvez seja útil começar com duas notas explicativas.

A primeira diz respeito à terminologia. Em sociedades capitalistas avançadas, não apenas a divisão do trabalho é extremamente complexa como também o é a distribuição de riqueza. A subsistência dos trabalhadores é atingida não apenas como um resultado direto do trabalho assalariado, mas também através de redistribuição, por meio do sistema financeiro (na forma de crédito, seguro privado, planos de previdência, etc.) e por meio do Estado (em forma monetária, através de taxas e sistemas de seguridade social, e em espécie, por meio de serviços providos pelo Estado). Num contexto como esse, a conexão direta entre trabalho e valor pode ser obscura. É comum aos analistas seguirem Marx ao classificar trabalho como "produtivo" e "improdutivo". A abordagem que adoto neste ensaio se baseia em insights provenientes do feminismo e estabelece uma distinção ligeiramente diferente. Trata-se de uma diferenciação entre trabalho que é diretamente produtivo para o capitalismo como um todo (que pode ser chamado de reprodutivo) e trabalho que é diretamente produtivo para capitalistas individuais (que, pela falta de um termo melhor, chamei de "diretamente produtivo”). Traço ainda uma distinção adicional entre trabalho que é remunerado e trabalho que não é remunerado. Defendo que (embora dependente de outras formas de trabalho para sua reprodução) a forma por excelência de trabalho que caracteriza o 
capitalismo é trabalho que produz valor para o capital e produz a renda que é necessária para a sobrevivência do trabalhador; trabalho cujo próprio desempenho contém, dentro de si, a contestação do tempo de trabalho entre trabalhador e capitalista e em cujo cerne reside a chave da expropriação, a experiência que Marx descreveu como "alienação" (um termo que se tornou, infelizmente, tão contaminado por outros significados, que já não pode ser mais usado com a precisão empregada por Marx); trabalho que, em outras palavras, está no centro do processo de acumulação. O local de trabalho não é, com certeza, o único lugar em que o trabalho confronta o capital, mas, pelo fato de o capital não poder ser acumulado sem o consentimento dos trabalhadores, é a esfera na qual o trabalho tem o maior poder potencial para arrancar concessões do capital (sem recorrer a um derramamento de sangue). Vejamos o Quadro 1 para

Quadro 1 - Trabalho - uma tipologia em diagrama

\begin{tabular}{|l|c|c|}
\hline & Trabalho remunerado & Trabalho não remunerado \\
\hline $\begin{array}{l}\text { Reprodutivo (produtivo } \\
\text { para a sociedade/capitalismo } \\
\text { em geral) }\end{array}$ & $\begin{array}{c}\text { Administração Pública e } \\
\text { trabalho de assistência pública } \\
\text { (incluindo ONG s); serviços } \\
\text { privados oferecidos } \\
\text { individualmente }\end{array}$ & $\begin{array}{c}\text { B } \\
\text { Trabalho doméstico (cuidado de } \\
\text { crianças, manutenção doméstica } \\
\text { etc., incluindo atividades culturais } \\
\text { não mercantis) }\end{array}$ \\
\hline $\begin{array}{l}\text { Diretamente produtivo (para } \\
\text { empresas capitalistas } \\
\text { individuais) }\end{array}$ & $\begin{array}{c}\text { C } \\
\text { Produção de mercadorias } \\
\text { incluindo distribuição }\end{array}$ & $\begin{array}{c}\text { Trabalho de consumo } \\
\text { D }\end{array}$ \\
\hline
\end{tabular}

uma representação diagramática.

A despeito de sua importância fundamental, encontrar um termo inequívoco para tal trabalho é surpreendentemente algo diverso. O termo "trabalho assalariado" abrange o trabalho que Marx designou como produtivo e improdutivo. Também exclui várias formas de trabalho (trabalho por peça, trabalho freelance, etc.) pagas em formas não assalariadas, que contribuem diretamente para a acumulação de capital e para a subsistência dos trabalhadores. Definir trabalho apenas em termos de ser produtivo ou não, no sentido de Marx, ignora a realidade de que há (como será discutido abaixo) uma quantidade considerável de trabalho não re- munerado que produz valor diretamente ao capital, sem contribuir para a subsistência do trabalhador. Em contrapartida, certamente, há trabalho remunerado que contribui para a subsistência sem criar valor diretamente ao capital. Depois de passar algum tempo considerando uma gama de alternativas, decidi-muito a contragosto e apenas para os objetivos deste ensaio - usar um termo abreviado para distingui-lo de outras formas de trabalho produtivo e assalariado. Com base na metáfora que usei para descrever a teoria do valor trabalho, refiro-me a ele a seguir, portanto, como trabalho que está "dentro do nó". Isso corresponde ao quadrante C no diagrama acima.

Trabalho "dentro do nó”, nessa definição, é o trabalho realizado diretamente para um empregador capitalista por um trabalhador que é dependente desse trabalho para subsistir e é, portanto, um adversário de linha de frente na luta entre capital e trabalho em relação a quanto tempo de trabalho deveria ser trocado por determinada quantidade de dinheiro. Isso pode parecer uma definição um pouco limitada. É, de fato, o tipo de definição que foi muito criticada nas décadas de 1960 e 1970, por excluir grandes grupos de trabalhadores que frequentemente viam a si mesmos como parte da classe trabalhadora, incluindo trabalhadores do setor público e alguns trabalhadores de serviços, cuja relação com a produção era indireta. Ao usá-la aqui, não estou afirmando que tais trabalhadores não são produtivos. Pelo contrário, muitas das tarefas que eles executam são essenciais para a reprodução do trabalho. Entretanto, a exposição desses trabalhadores à dura lógica do capitalismo pode ser um pouco atenuada, seja porque eles estão trabalhando sob formas antigas de emprego (por exemplo, como empregos domésticos ou como pequenos produtores de mercadorias), seja 
porque são empregados pelo Estado para oferecer serviços ainda não mercadorizados.

Naturalmente, tais formas de trabalho ainda existem, mas, como argumentei em outro momento (Huws, 2012), na atual onda de mercadorização, essas formas de trabalho estão diminuindo, e os trabalhadores que as executam estão sendo rapidamente arrastados para "dentro do nó". Em outras palavras, a mercadorização de serviços públicos tem produzido uma grande mudança de trabalho do quadrante A para o quadrante C, no diagrama acima.

Como já afirmei em outra ocasião (Huws, $1982^{7}$ ), essa não é a única mudança que está acontecendo. A mercadorização mais geral de bens de consumo e serviços também tem acarretado grandes mudanças do quadrante B para o quadrante $\mathrm{D}$, transformando a natureza de trabalho não remunerado, de uma produção direta de valores de uso para membros das famílias, em compra de mercadorias no mercado, acarretando uma relação direta com a produção capitalista e atividades de distribuição. Em mais uma reviravolta, tem havido também uma mudança do trabalho do quadrante $\mathrm{C}$ para o quadrante $\mathrm{D}$, visto que as companhias capitalistas de produção e distribuição reduziram seus custos de trabalho, aumentando a exploração de seus trabalhadores remunerados ao externalizar cada vez mais tarefas a consumidores, que têm de realizá-las como atividades de autosserviço não remuneradas. Em um processo paralelo, medidas de austeridade também estão levando a uma mudança de atividade do quadrante A para o quadrante $\mathrm{B}$, o que, por sua vez, coloca mais pressões sobre a mudança ulterior de B para C.

Assim, o trabalho "dentro do nó" constitui um subconjunto de todo o trabalho e está se expandindo rapidamente rumo a se tornar a esmagadora maioria do trabalho remunerado.

Minha segunda nota de advertência referese ao perigo de se extrapolar uma tipologia do trabalho em uma tipologia de trabalhadores e, consequentemente, em uma tipologia de classe. Enquanto parte de meu objetivo é classificar dife-

\footnotetext{
${ }^{7}$ Reproduzido em Huws (2003, p.35-41).
}

rentes formas de trabalho em sua relação com a acumulação de capital e com a subsistência dos trabalhadores, ao cumpri-lo não pretendo produzir uma classificação de trabalhadores que possa ser lida de maneira simplista a partir dessa tipologia. A maioria dos trabalhadores se envolve em vários tipos diferentes de trabalho, remunerados e não remunerados, simultaneamente e ao longo do curso de suas vidas, transpondo essas categorias simples. Mais importante ainda, a maioria dos trabalhadores vive em lares onde diferentes tipos de trabalho são realizados por diferentes membros da família, algum dos quais, em dado momento, pode estar desempregado. Uma grande questão é se os membros dessa família percebem ou não a si mesmos, ou podem ser percebidos por outros, como pertencentes à classe trabalhadora.

\section{A RELAÇÃO ENTRE TRABALHO DIGITALE OUTRAS FORMAS DE TRABALHO}

Antes de iniciar essa análise, vale dizer que o trabalho digital não pode ser entendido como uma forma destacada de trabalho, separada hermeticamente do resto da economia. Como afirmei em outro momento (Huws, 1999), a existência de uma esfera visível, separada de trabalho não manual, não é prova de um novo campo de atividade econômica "baseado no conhecimento", "imaterial" ou "sem peso"; é simplesmente uma expressão do crescimento da complexidade da divisão do trabalho, com a fragmentação de atividades em tarefas separadas, tanto mentais quanto manuais, crescentemente passíveis de serem dispersas geográfica e contratualmente para diferentes trabalhadores, que podem mal saber da existência um do outro. Esse é um processo contínuo, com cada tarefa sujeita a divisões ulteriores entre funções mais criativas e (ou) de controle, por um lado, e outras mais de rotina e repetitivas, por outro.

Ademais, se houve claramente uma enorme expansão de trabalho não manual, de rotina e não qualificado, em contrapartida, ele permaneceu uma minoria de todo o trabalho. A crescente visibilida- 
de para observadores, nas economias desenvolvidas, de trabalho aparentemente desmaterializado, dependente de tecnologias de informação e comunicação (TICs), tem servido, algumas vezes, para obscurecer a realidade de que essa atividade "virtual" é dependente de uma base altamente material de infraestrutura física e de mercadorias manufaturadas, a maioria das quais é produzida fora de seu campo de visão, nas minas da África ou da América Latina, nas sweatshops ${ }^{8}$ da China e outros locais no mundo em desenvolvimento. A internet não poderia ser acessada por ninguém sem a geração de energia, cabos, satélites, computadores, comutadores, telefones celulares e milhares de outros produtos materiais, sem a extração de matérias-primas que formam essas mercadorias, sem o lançamento de satélites ao espaço para carregar seus sinais, sem a construção de edifícios nos quais essas mercadorias são projetadas e montadas e de onde são vendidas, e a manufatura e operação de veículos nos quais são distribuídas. A produção física de mercadorias materiais é ainda o método preferido do capitalismo para gerar lucro; ela ainda está crescendo e parece provável que continue a empregar a maior parte da força de trabalho mundial. Há, ademais, um continuum entre tarefas que envolvem predominantemente o exercício da força física ou destreza e aquelas que envolvem agilidade mental, compromisso ou concentração. Há poucos empregos que não exigem dos trabalhadores que tragam seus próprios conhecimentos, discernimento e inteligência para a atividade em questão, e são ainda menos numerosos os trabalhos que não envolvem alguma atividade física, mesmo que seja apenas falar, ouvir, observar uma tela ou bater em teclas.

Dito isso, uma grande e crescente parte da força de trabalho está envolvida na execução de "trabalho digital", do qual os produtos são intangíveis. Muito desse trabalho é mal remunerado e não qualificado. É importante, portanto, entender que papel seu trabalho desempenha no capitalis-

${ }^{8}$ N.T.: literalmente "fábricas do suor", o termo sweatshop designa indústrias onde se efetivam formas de superexploração do trabalho. mo global, qual é a composição dessa força de trabalho, como ela está mudando e que lealdades de classe esses trabalhadores podem expressar.

\section{VALOR}

Em termos simples, pode-se dizer que existem, principalmente, três modos pelos quais as empresas podem gerar lucro no capitalismo, sendo que os dois primeiros também existiram em outros sistemas. Trata-se de rendas [rent], comércio e geração de mais-valia através da produção de mercadorias. Uma vez que é a forma paradigmática de geração de valor no capitalismo, é a produção de mercadorias que recebe a maior atenção de analistas marxianos. Se o valor está visivelmente sendo gerado a partir de alguma atividade, a tendência é buscar pela mercadoria em sua fonte. Se a mercadoria não pode ser facilmente identificada, ou se ela não parece ser produzida através da extração de mais-valia de trabalhadores remunerados, então se conclui, algumas vezes, que isso significa que a teoria do valor trabalho de Marx não se aplica e que está obsoleta ou tem necessidade de adaptação. Todavia, antes de saltar à conclusão de que teorias inteiramente novas são necessárias para explicar as atividades on-line, vale a pena analisar essas últimas em relação às formas tradicionais de geração de valor para conferir se elas se encaixam nessas categorias.

\section{RENDAS}

O ponto de partida para muitas das discussões atuais sobre o valor que é gerado na internet é a indiscutível realidade de que companhias online, como Google e Facebook, são enormemente lucrativas. Se elas estão gerando lucros, argumenta-se, deve ser porque alguma mercadoria está sendo produzida, o que, por sua vez, coloca a questão sobre o que seriam precisamente tais mercadorias e o trabalho que as produz. No caso do Google e do Facebook, a principal fonte de ganhos são re- 
ceitas advindas de publicidade, que podem ser atingidas com grande precisão, resultantes das cada vez mais sofisticadas análises dos dados gerados pelos usuários. Aqui, o conceito de Smythe (1977) da "mercadoria audiência" tem sido aproveitado por certo número de comentadores, incluindo Fuchs (2012). Originalmente desenvolvido como parte de uma tentativa marxiana de entender a economia da publicidade no rádio e na TV comerciais, esse conceito retrata a audiência midiática como a mercadoria que é vendida aos anunciantes para gerar receita: "porque o poder da audiência é produzido, vendido, comprado e consumido, ele controla o preço e a mercadoria” (Smythe, 1981, p.233). Fuchs aplica essa lógica à internet: “... o tempo de trabalho produtivo que é explorado pelo capital [...] envolve [...] todo tempo que é gasto online pelos usuários”. E continua: “... a taxa de exploração converge rumo ao infinito se os trabalhadores são não remunerados. Eles são infinitamente explorados". Outros colaboradores do debate do trabalho digital sugerem que a "reputação" (Hearn, 2010) ou mesmo a vida produzida pelo "biotrabalho" (Morini; Fumagalli, 2010) tornaram-se mercadorias.

O conceito de Smythe, indubitavelmente, gerou insights úteis acerca da natureza da mídia de massa, mas também trouxe certa confusão. A suposição subjacente entre os seguidores de Smythe parece ser a de que o termo "mercadoria" pode ser usado para se referir a qualquer coisa que possa ser comprada e vendida. Há certa lógica circular operando aqui. Uma vez que Marx (1867) declara que "mercadorias não são mais que trabalho cristalizado" e que "um bem apenas tem valor porque há trabalho objetivado ou materializado nele", deve-se concluir, de acordo com essa lógica, que qualquer coisa descrita como uma mercadoria deve ser o resultado de trabalho produtivo. Mas quão útil é tal concepção ampla do termo?

Parece-me que, para entender a natureza distinta da forma mercadoria no capitalismo, uma definição um pouco diferente precisa ser usada. Defini mercadorias, em outro momento (Huws, 2003, p.17), como "produtos ou serviços padronizados à venda em mercados cuja venda irá gerar lucros que aumentam em proporção à escala de produção". Essa definição distingue mercadorias capitalistas como fundamentalmente diferentes daquelas produzidas em outros sistemas. Um carpinteiro tradicional, que faz cadeiras e as vende diretamente ao público, recebe mais ou menos o mesmo lucro em cada cadeira. O capitalista que abre uma fábrica e emprega trabalhadores para a produção em massa de cadeiras tem de fazer um investimento em maquinaria, edifícios, e assim por diante, e não terá um lucro na primeira cadeira, mas quanto mais cadeiras forem produzidas nessa fábrica, maior será o lucro em qualquer uma delas. Isso dá às cadeiras produzidas na fábrica um caráter fundamentalmente diferente, em relação a seu valor, daquelas produzidas pelo artesão individual. Há uma série de serviços, incluindo os intangíveis (tais como apólices de seguro ou softwares), que tem a mesma característica das mercadorias. Éa relação social na qual elas são produzidas (o trabalho coagido de trabalhadores assalariados sob o controle do capitalista) que lhes concede esse caráter. ${ }^{9}$

Se elas não derivam da venda de mercadorias, como podemos entender os lucros feitos por redes sociais online ou companhias de mecanismos de busca? Há uma explicação alternativa, e que tem extensos antecedentes no mundo off-line: eles derivam de rendas de aluguel [rent]. Um simples exemplo histórico de uma maneira semelhante de gerar rendimento poderia ser fornecido pelo mercado de rua, onde o aluguel [rent $]$ cobrado por espaços de tendas é maior em áreas onde a maioria dos clientes (ou os clientes mais ricos) irá passar. Exemplos concretos podem ser encontrados na Quinta Avenida de Nova Iorque, na Oxford Street de Londres, ou em qualquer outra rua com um grande e lucrativo trânsito de pessoas: quanto mais bem movimentado o local, maior o aluguel. Por mais de um século, propriedades que margeiam rodovias de tráfego intenso foram capazes de fazer dinheiro ao alugar espaço para outdoors. Essas companhias não seguem, simplesmente, a mesma

${ }^{9}$ Esse argumento é feito de maneira ligeiramente diferente na discussão acerca da distinção entre trabalho produtivo e improdutivo realizada por Marx (1863). 
lógica, embora com locais que são virtuais, em vez de pavimentados, e com meios bem mais sofisticados de identificar os consumidores mais lucrativos e de adquirir conhecimento sobre seus desejos? O valor que se reverte para a rede social e para sites de mecanismos de busca deriva, de fato, em última análise, da mais-valia produzida pelo trabalho. Mas esse é o trabalho de trabalhadores que produzem as mercadorias que são anunciadas nesses sites, não o trabalho das pessoas que usam os sites. ${ }^{10}$

Alguns participantes do debate sobre trabalho digital, como Arvidsson e Colleoni (2012), contestam a noção de Fuchs de que usuários de mídias sociais estão produzindo mais-valia. Eles também argumentam que o valor gerado pode ser mais bem considerado como rendas de aluguel [rent]. Entretanto, eles usam o termo "renda" [rent] para se referir ao valor que se reverte aos investidores financeiros nessas empresas. Mas, nesse aspecto, eles não dizem o que distingue as companhias on-line de quaisquer outras companhias cotadas nas bolsas de valores e que atraem investimentos financeiros. Na tentativa de classificar o que, precisamente, gera o valor que atrai tais investidores, eles desenvolvem uma explicação segundo a qual "[...] plataformas de mídias sociais, como o Facebook, funcionam como canais por meio dos quais investimentos afetivos por parte da multidão podem ser convertidos em formas 'objetificadas' de afeto abstrato que sustentam avaliações financeiras". Argumentam ainda que tais companhias ganham suas parcelas de "mais-valia produzida socialmente" por meio "da habilidade de atrair investimentos afetivos [...] da multidão ou do público global". Esse modelo, um tanto complicado, escamoteia a questão bem mais prosaica sobre quem está pagando quem para o quê, no intuito de gerar retorno sobre o investimento dos acionistas. Em minha opinião, pode-se responder

${ }^{10}$ Exceto em algumas circunstâncias especiais, tais como o caso do modelo pay per click, em que os trabalhadores são pagos para ir ao Facebook e clicar em "curtir" determinados websites comerciais. Mas aqui eles não são empregados pelo Facebook, mas por companhias ligadas a esses websites comerciais, que têm alguma mercadoria a vender. Portanto, eles deveriam ser mais precisamente considerados como pertencentes à cadeia de valor dessas companhias produtoras de mercadorias. de forma bem mais simples dizendo que são os publicitários (produtores de mercadorias para venda) que estão pagando as mídias sociais e as companhias de mecanismos de busca pela oportunidade de anunciar para seus usuários.

Há diversas outras atividades que contam com alguma combinação de cobrança pelo uso com taxas de comissão a prestadores de serviços e (ou) a usuários de serviços e (ou) a anunciantes - em outras palavras, rendas de aluguel [rent].

\section{COMÉRCIO}

O comércio envolve adquirir algo por um preço (o que também inclui roubá-lo) e vendê-lo por um preço maior, obtendo um lucro nesse processo. Algumas formas de roubo, como a apropriação da propriedade intelectual de outras pessoas, podem acontecer on-line. No entanto, há também um grande número de companhias que vendem online (Amazon é provavelmente a mais famosa) de uma forma que reproduz o comércio off-line. De fato, muitos comerciantes agora compram e vendem tanto on-line quanto off-line. Embora possa haver alguma indefinição de fronteiras tradicionais entre as atividades de distribuição de fabricantes, atacadistas e varejistas, e alguns processos de trabalho possam ser bem diferentes, não há nada misterioso em relação a como o valor é gerado por tais companhias. A escala de muitas dessas companhias, acrescida ao fato de que elas tiveram de colocar em funcionamento uma ampla infraestrutura para processar pagamentos internacionais, significa que algumas delas têm sido capazes de diversificar em atividades rentistas, o que tem criado, por sua vez, as bases para novas formas de produção de mercadorias, discutidas na próxima seção.

\section{PRODUÇÃO DE MERCADORIAS}

Isso nos leva à categoria final: valor que é gerado da produção de mercadorias. Aqui, o analista que procura isolar o papel do trabalho digital 
na criação de valor se vê diante de desafios consideráveis. A disseminação da computação na maioria dos setores da economia, combinada com o uso quase universal de telecomunicações para a comunicação, significa que há poucas atividades econômicas que não envolvem algum elemento de trabalho digital, não importa se eles ocorrem em fazendas, fábricas, depósitos, escritórios, lojas ou em veículos em movimento. Ademais, essas atividades estão ligadas umas às outras em cadeias complexas que atravessam as fronteiras entre empresas, setores, regiões e países. Traçar a conexão de qualquer atividade de volta às suas origens, ou ir adiante em direção à mercadoria final para a qual a produção tem contribuído, não é tarefa fácil. No entanto, não é, de forma alguma, impossível. Uma abordagem útil aqui é analisar as atividades econômicas em termos funcionais. ${ }^{11}$

As funções de pesquisa e desenvolvimento e de design, por exemplo, criam, claramente, insumos diretos para o desenvolvimento de novas mercadorias (ou para a adaptação das antigas). Grande parte do trabalho envolvido nessas atividades, nos dias de hoje, se insere na categoria de trabalho digital, que envolve ferramentas baseadas em computadores e (ou) é entregue em formato digital para os trabalhadores que vão levá-lo às próximas fases de produção. O mesmo vale para atividades cujo objetivo é desenvolver conteúdo para livros, filmes, CDs ou outros produtos culturais. O trabalho digital também está envolvido de várias maneiras nos processos de produção, quer se trate da operação de ferramentas de comando digital, da manutenção de software, da geração de produtos imateriais ou da supervisão de outros trabalhadores ocupados nesses processos.

Quando se trata de atividades de "serviço", é útil (embora cada vez mais difícil) fazer uma distinção geral entre aqueles que contribuem diretamente para a produção (como a limpeza do chão de fábrica ou manutenção das máquinas), aqueles que contribuem para a manutenção ou gestão da

${ }^{11}$ Discuti o conceito de "função de negócio" e sua relação com a análise marxista em algumas publicações. Ver, por exemplo, Huws $(2006,2007)$. força de trabalho (tais como processamento de dados da folha de pagamento ou recrutamento de pessoas ou treinamento), aqueles que contribuem para a gestão mais geral da empresa (incluindo a gestão financeira), aqueles que estão envolvidos em atividades relacionadas a compras, vendas e marketing, e aqueles que estão envolvidos com a distribuição. Todas essas categorias incluem atividades que são realizadas on-line e (ou) usam uma combinação de tecnologias de informação e comunicação. No entanto, estão se tornando mais e mais difíceis de serem distinguidas, por diversas razões ligadas entre si.

A primeira delas é a natureza cada vez mais genérica de muitos processos de trabalho. Trabalhadores que alimentam dados numéricos em um teclado, por exemplo, podem estar fazendo isso para um banco, um departamento de governo ou uma indústria, para fins totalmente desconhecidos para eles. Operadores de teleatendimento podem estar usando scripts padrões para lidar com vendas, atendimento ao cliente, cobrança de dívidas, pesquisas governamentais, levantamento de fundos ou uma variedade de outras funções, cortando transversalmente qualquer sistema puro, que poderia classifica-los em diferentes categorias por função. Os engenheiros de software podem estar trabalhando no desenvolvimento de novos produtos, ou na manutenção dos já existentes.

Intimamente ligada a essa forma de padronização está a crescente propensão de tais atividades serem terceirizadas, muitas vezes para empresas que reúnem uma série de funções diferentes para clientes diversos em clusters de atividades realizadas em centros de serviços compartilhados. A possibilidade de esses e outros serviços serem realizados on-line borrou ainda mais a distinção entre os serviços prestados às empresas e aqueles fornecidos diretamente aos clientes finais. Se qualquer um pode encomendar produtos on-line, para serem entregues à porta, vindos de um depósito central, então a distinção entre "atacado" e "varejo” se torna artificial. De forma similar, há uma gama crescente de produtos imateriais padronizados, que vão desde licenças de software a contas 
bancárias e apólices de seguro, que pode ser prontamente vendida tanto para indivíduos como para empresas.

A existência de plataformas on-line através das quais o trabalho pode ser coordenado levou ao desenvolvimento de uma forma extrema de subdivisão de tarefas, às vezes conhecida como microtrabalho, trabalho de massa [crowd work] (Kittur et al, 2013) ou crowd-sourcing (Holts, 2013).

Se tais atividades, ainda que dispersas, são realizadas por trabalhadores remunerados, a serviço de empresas criadas para obter um lucro, então elas podem ser atribuídas, sem problemas, à categoria de trabalho que produz diretamente mais-valia para o capital - o trabalho "dentro do nó". No entanto, como as fronteiras entre produção, distribuição e consumo tornam-se cada vez mais vagas, e a mesma atividade pode ser realizada indistintamente por trabalhadores remunerados e não remunerados, essa colocação simples precisa de alguma modificação. Marx foi um tanto ambivalente sobre o trabalho de distribuição, considerando como produtivos os trabalhadores de transporte, mas não os do varejo. No entanto, em certo momento, nos Grundrisse, afirmou que todo o processo de trazer um produto para o mercado deve ser considerado como trabalho produtivo: "Considerada economicamente, a condição espacial, trazer o produto para o mercado pertence ao próprio processo de produção. O produto está realmente pronto apenas quando está no mercado." (Marx, 1857). ${ }^{12}$

Seguindo essa lógica, uma ampla gama de funções encontradas em uma empresa moderna pode ser atribuída a essa categoria diretamente produtiva, incluindo marketing, gestão de logística, distribuição, transporte, atendimento ao cliente, vendas no varejo e atacado (on-line ou off-line) e

${ }^{12}$ Deve-se ressaltar que há controvérsias na interpretação dessa passagem. Frequentemente se considera que Marx faz aqui uma exceção especial relacionada aos trabalhadores do transporte (talvez porque eles fossem um grupo com forte potencial de organização sindical - um potencial que foi mais do que efetivado no século $\mathrm{XX}$ quando os trabalhadores do transporte tiveram um papel-chave nas ações coletivas industriais). De minha parte, considero que o argumento se aplica igualmente a outras formas de trabalho envolvidas em levar os produtos ao mercado, muitas das quais eram inconcebíveis no tempo em que Marx escrevia. serviço de entrega, em suma, toda a cadeia de valor do portão da fábrica (ou do local de desenvolvimento de software) ao consumidor final deve ser considerada como trabalho produtivo. No entanto, apenas aquelas tarefas realizadas por trabalhadores remunerados estão "dentro do nó", onde sua relação com o capital é direta e (real ou potencialmente) contestada.

\section{TRABALHO}

Qualquer tentativa de classificar as diferentes formas de trabalho tem de começar enfrentando a questão extraordinariamente difícil de saber o que o trabalho realmente é. A palavra em si abrange um espectro vasto de significados, desde o esforço físico de dar à luz, em um extremo, à participação formal em um emprego ou à representação política das pessoas que fazem isso, no outro.

Se o considerarmos em referência a atividades que são, real ou potencialmente, pagas com salários em um "mercado de trabalho", então temos de incluir uma grande variedade de atividades que a maioria das pessoas realiza sem remuneração, incluindo o sexo, o cuidar de crianças, cozinhar, limpar, a jardinagem, cantar, fazer as pessoas rirem e discorrer longamente sobre temas que nos interessam.

Se aplicarmos um filtro mais subjetivo e tentarmos excluir as atividades que são realizadas por prazer, somos confrontados, então, com a estranha realidade de que a mesma atividade pode ser vivenciada como uma obrigação ou uma alegria, sob circunstâncias diferentes, e, ainda, que algumas atividades, remuneradas ou não remuneradas, podem ser simultaneamente onerosas e agradáveis. O bebê, por exemplo, pode dar a você um sorriso radiante enquanto sua fralda malcheirosa está sendo trocada; a longa viagem solitária de um motorista de caminhão, de repente, pode lhe oferecer uma emocionante bela visão da paisagem; o trabalho físico intenso, em ambientes desagradáveis, pode engendrar uma camaradagem entre os trabalhadores que deixa um caloroso conforto muito 
depois de a dor muscular diminuir; resolver um problema complicado pode liberar um súbito arroubo de satisfação, mesmo que o problema não seja daquele que o resolveu.

Outra dimensão que pode ajudar a distinguir "trabalho" e "prazer" é se a atividade é realizada de forma voluntária ou por coerção, sob a direção de outra pessoa ou organização. Aqui, novamente, o que parece uma simples distinção se torna notavelmente difícil de ser verificada na prática. Uma dificuldade resulta das maneiras historicamente determinadas pelas quais coisas - como os papéis de gênero, os conceitos de dever, ou mesmo divisões de trabalho baseadas em castas são internalizadas, tornando padrões de poder e coerção invisíveis para todas as partes e, de fato, dando a muitos atos de serviço uma qualidade subjetiva de dádivas de amor livremente oferecidas, mesmo quando a análise objetiva pode sugerir que envolvem a exploração do trabalho de uma pessoa por outra. A coerção também pode ser exercida de forma mais indireta. Um jogador viciado, por exemplo, pode perceber sua compulsão como gerada internamente, não reconhecendo as pressões sociais que o impelem. O mesmo poderia ser dito, talvez, de muitas das atividades online nas quais as pessoas gastam muito tempo, incluindo jogos on-line e a interação com outras pessoas em sites de mídia social. É, talvez, uma alusão a essas pressões sociais que leva tantos comentadores, nos debates de mídia digital, a insistir que essas atividades não remuneradas são uma forma de trabalho "livre" (Terranova, 2000).

O trabalho não remunerado não é, naturalmente, um fenômeno novo. No entanto, tem recebido atenção bastante irregular de estudiosos marxistas, exceto como uma espécie de repositório vestigial de relações sociais pré-capitalistas, a partir das quais, depois, emergiu o trabalhador assalariado. Afora debates entre historiadores sobre a escravidão, muito da atenção dada ao trabalho não remunerado, até recentemente, se deu no contexto do que poderia ser vagamente chamado de "trabalho reprodutivo", em particular nos debates feministas durante os anos de 1970. Nessas discus- sões, a principal questão levantada foi se o trabalho doméstico [housework] não remunerado poderia ser considerado como produtor de mais-valia, pois, sem ele, o capitalismo não poderia existir. A reprodução da força de trabalho depende fundamentalmente, argumentou-se, de trabalho não remunerado no lar, não apenas por criar a próxima geração de trabalhadores, mas também para fornecer a alimentação, limpeza e serviços de manutenção do corpo que permitem que a força de trabalho atual aja com eficiência no mercado de trabalho. Em 1976, Weinbaum e Bridges publicaram um artigo pioneiro, no qual argumentaram que, no contexto do capital monopolista, muito desse trabalho não envolve apenas a produção de serviços em casa, mas também consumir mercadorias produzidas no mercado. O conceito de "trabalho de consumo", no qual o trabalho não remunerado é substituído por aquilo que era anteriormente o trabalho remunerado dos trabalhadores de distribuição, é algo que continuei a desenvolver no final dos anos de $1970^{13} \mathrm{e}$, nesse momento, afirmo que é relevante para a compreensão de algumas das novas formas de trabalho não pago que ocorrem on-line e off-line.

Baseado em alguns desses trabalhos, proponho aqui uma tipologia um tanto provisória do trabalho não remunerado, na esperança de que possa fornecer um ponto de partida para uma categorização que irá trazer alguma clareza a esses debates.

A primeira categoria é o trabalho que é realizado independentemente do mercado para a produção de valores de uso em casa - a categoria de trabalho localizado no Quadrante B no diagrama acima. É "improdutivo" no sentido de que não produz valor direto para o capital na forma de maisvalia a partir do trabalho direto de alguém, mas sim "reprodutivo" no sentido de que é necessário para a reprodução da força de trabalho. Inclui muitas das tarefas tradicionalmente realizadas na agricultura de subsistência e no trabalho doméstico. Se alguém é empregado, pelo usuário direto do serviço, para fazer esse tipo de trabalho (por

${ }^{13}$ Ver, por exemplo, Huws (1982), republicado em Huws (2003). 
exemplo, uma empregada doméstica, uma babá, um faxineiro ou jardineiro), esse trabalhador é, na opinião de Marx, um trabalhador improdutivo; mas se for empregado por meio de um intermediário capitalista (por exemplo, uma creche comercial, ou uma empresa de limpeza ou jardinagem), então esse trabalhador desloca-se para a categoria de trabalhador produtivo ${ }^{14}$ (em termos do diagrama acima, do Quadrante A para o Quadrante C). Na medida em que a manutenção da saúde emocional de uma família e a manutenção das redes sociais em que está inserida é uma parte necessária para assegurar a sobrevivência de um lar, então uma série de atividades não físicas pode ser incluída nessa categoria. Muitas dessas atividades são realizadas on-line nos dias de hoje, assim, pelo menos uma parte da atividade de redes sociais on-line pode ser identificada por essa categoria (representada pelo Quadrante B no diagrama).

A segunda categoria de trabalho não remunerado é a que me referi acima como "trabalho de consumo” (Quadrante D no diagrama). Isso implica o consumidor assumir tarefas no mercado que anteriormente eram realizadas por trabalhadores pagos como parte dos processos de distribuição da produção de mercadorias. Como essas tarefas são necessárias para a distribuição dessas mercadorias e para aumentar os lucros das empresas produtoras de mercadorias, ao eliminar as formas de trabalho que antes eram remuneradas, há fortes argumentos para classificar esse tipo de trabalho como "produtivo", mesmo quando não é remunerado. No entanto, por não gerar renda diretamente para o trabalhador, tem de ser tratado de forma diferente do trabalho remunerado em relação à sua contribuição para a subsistência, um tema a que voltarei adiante. Está, em outras palavras, “fora do nó”. Como já foi mencionado, quantidades crescentes de trabalho de consumo são realizadas online, pois a internet abriu um leque de novas formas de externalizar ${ }^{15}$ trabalho à distância.

${ }^{14}$ Ver Marx (1861-1864a).

${ }^{15}$ Aqui, uso o termo externalizar fazendo referência às maneiras pelas quais os empregadores aumentam a produtividade de seus trabalhadores remunerados através da transferência de algumas ou de todas as tarefas des-
A terceira categoria compreende o trabalho criativo. Aqui, Marx (1861-1864b) tornou sua posição clara.

Milton, por exemplo [...] foi um trabalhador improdutivo. Em contraste, o escritor que fornece trabalhos fracionados sob encomenda para seu editor é um trabalhador produtivo. Milton produziu $O$ Paraíso perdido do mesmo modo que um bicho-da-seda produz seda, como expressão de sua própria natureza. Mais tarde, ele vendeu o produto por cinco libras e, nesse sentido, tornou-se um comerciante de uma mercadoria [...] A cantora que canta como um pássaro é um trabalhador improdutivo. Se ela vende seu canto por dinheiro, ela é, nesse sentido, um trabalhador assalariado ou um comerciante de mercadorias. Mas a mesma cantora, quando empregada por um empresário que usa seu canto com vistas a obter dinheiro, é um trabalhador produtivo, pois ela produz diretamente o capital.

De acordo com essa concepção, na medida em que é realizado para fins de autoexpressão, o trabalho artístico não remunerado, como "blogar" ou postar fotos, música ou vídeos na internet, vai diretamente para a categoria de trabalho "improdutivo” de Marx (que eu prefiro considerar como trabalho reprodutivo não remunerado, produzindo valores sociais de uso). Se o produto desse trabalho for posteriormente vendido, ou roubado, para se tornar a base de uma mercadoria, isso também não muda essa condição. Apenas se o trabalhador for contratado para fazer o trabalho por um salário é que sua atividade se torna trabalho produtivo, no sentido do termo utilizado por Marx - ou seja, ela muda do Quadrante B para o Quadrante C no diagrama. Como Ross assinalou, muitos trabalhadores artísticos podem oscilar entre essas formas: "os criativos enfrentaram esse tipo de escolha, desde o século XVIII, quando o aparecimento de mercados comerciais de cultura ofereceu a eles a opção de ganhar a vida penosamente como escriba na Pope’s Gub Street ou construir uma relação de reputação com um público inconstante.” (Ross,

ses últimos para consumidores não pagos, na forma de autosserviços, seja pela operação de máquinas, como caixas eletrônicos ou autosserviços de supermercados, ou atividades online, como a compra de ingressos, preenchimento de declarações de imposto ou encomenda de mercadorias 
2012, p.15). O fato de que a mesma pessoa faça os dois tipos de trabalho não invalida, contudo, a distinção entre eles. O trabalho criativo, portanto, tem de ser visto de modo a abranger um número de diferentes posições no mercado de trabalho, ${ }^{16}$ incluindo o autoemprego, o emprego remunerado e a pequena produção mercantil, o que leva, muitas vezes, a identidades contraditórias nos trabalhadores criativos.

A mesma lógica aplica-se até mesmo ao caso muito discutido do "trabalho livre", que construiu a internet, muito do qual foi projetado por desenvolvedores de software idealistas, que doaram seu trabalho de graça, na crença de que estavam criando um benefício comum para a humanidade (em outras palavras, eles estavam produzindo valor de uso social sem remuneração, colocando-se no Quadrante B no diagrama). Como disse Marx (apud Ross, 2012), “[...] trabalho com o mesmo conteúdo pode ser tanto produtivo quanto improdutivo". Nesse caso, parece que, embora os resultados de seu trabalho tenham sido apropriados pelo capital para incorporá-los em novas mercadorias, seu trabalho não remunerado original não pode ser considerado como produtivo no sentido de produzir mais-valia para o capital em condições coercitivas (ou seja, não está “dentro do nó”). Em vez disso, o valor que foi produzido a partir dele deveria mais corretamente ser colocado na categoria de comércio, o que, como já mencionei acima, também inclui o roubo.

A quarta forma (ainda que sobreposta) de trabalho não remunerado, que é cada vez mais discutida, é o uso generalizado de estágio não remunerado ou de trabalho "voluntário"17 Situado ambiguamente entre a educação e a autopromoção, ele é, sem dúvida, utilizado de forma altamente exploradora por parte dos empregadores como um substituto direto para o trabalho remunerado. Algumas vezes, a coerção direta implica obrigar o trabalhador a se comprometer com "estágios não remunerados", por exemplo, as agências estatais de

\footnotetext{
${ }^{16}$ Analisei minuciosamente a questão em Huws (2010).

${ }^{17}$ Ver, por exemplo, Perlin (2011).
}

procura de emprego que ameaçam a retirada do seguro desemprego daqueles que recusam aceitar tais estágios. No entanto, como o já discutido trabalho de consumo não remunerado, ainda que contribua claramente para a produção de valor na produção de mercadorias, ele não desempenha nenhum papel na geração atual de renda para o trabalhador e deve, portanto, ser considerado como "fora do nó", mesmo se está produzindo valor indiretamente para o trabalhador não remunerado na forma de "empregabilidade".

É claro que, a fim de dar sentido à relação de trabalho não remunerado para o capital, temos de levar em conta a terceira corda do nó, que constitui a teoria do valor trabalho: a subsistência do trabalhador ou "vida".

\section{VIDA}

A questão de como o trabalhador paga os custos de subsistência está surpreendentemente ausente da maioria dos debates sobre o trabalho digital "livre". Talvez porque os próprios pesquisadores, em muitos casos, têm empregos acadêmicos estáveis, a maioria dos autores que contribuiu para essas discussões não se pergunta como esses trabalhadores dedicados, que construíram a internet com o seu trabalho livre, realmente ganham a vida. Também não é sempre claro, entre aqueles que defendem um "Creative Commons" na internet, para o qual todos os autores deveriam doar gratuitamente seu trabalho, como se espera que esses autores paguem o aluguel e sustentem suas famílias.

No entanto, a teoria do valor trabalho não pode ser operacionalizada sem essa informação. A fim de saber quanto e como a mais-valia é gerada a partir de qualquer unidade de trabalho, precisamos saber o custo de reprodução desse trabalhador e quanto do seu tempo de trabalho é "tempo de trabalho necessário" exigido para manter sua vida. Só então poderemos ver o quanto resta para ser apropriado como mais-valia e começar a formular exigências para sua redistribuição. Isso não é, obviamente, um cálculo mecânico. É perfeita- 
mente possível que os trabalhadores sejam empregados abaixo do custo de subsistência. O que faz o empregador se importar se eles morrerem, se há muito mais de onde eles vieram? Da mesma forma, é possível que grupos bem organizados de trabalhadores com habilidades escassas se sobressaiam, a despeito de suas limitações, e exijam do capital um salário maior do que o necessário para a mera sobrevivência - e que lhes permita, até mesmo, empregar outros trabalhadores como empregados domésticos. No entanto, o capitalismo como um sistema, no modelo de Marx, requer uma classe trabalhadora que é obrigada a vender o seu trabalho a fim de sobreviver, assim como requer capitalistas que sejam capazes de empregar esse trabalho para produzir mercadorias cujo valor coletivo no mercado excede o salário total da força de trabalho necessária para produzi-las. E é a experiência direta de ser obrigado a disputar com o empregador a posse de seu tempo de trabalho que produz a alienação suscetível de conduzir à consciência de classe. Não é possível se esquivar, portanto, da questão do "tempo de trabalho necessário".

Mas, mesmo em Marx, esse é um conceito bem problemático. Uma razão para isso é que, embora os trabalhadores normalmente entrem no mercado de trabalho como indivíduos separados, sua subsistência ocorre em domicílios onde várias pessoas podem coabitar. ${ }^{18}$ Pelo fato de esses domicílios variarem consideravelmente em tamanho, composição e no número de membros ocupados com trabalho remunerado, o mesmo salário pode ter de se esticar para cobrir a subsistência de um número variável de pessoas. Marx e Engels (1845) discutiram a divisão "natural" (sic) do trabalho na família, o que eles consideraram como uma forma de "escravidão dissimulada", que pode até mesmo ser considerada como a origem de toda propriedade. A partir dessa premissa, de que as mulheres e as crianças são propriedades do chefe de família, foi possível para Engels (1956) concluir que: "[...] antigamente, a compra e venda da força de trabalho era uma relação entre pessoas livres; ago-

${ }^{18}$ Escrevi mais extensamente sobre isto em Huws (2012). ra, menores e crianças são comprados, o trabalhador vende agora esposa e filho - ele se torna um negociante de escravos.” (1956, p.69).

No século XXI, quando as mulheres representam quase metade da força de trabalho nos países mais desenvolvidos e apenas uma minoria é economicamente inativa, tal explicação não é suficiente. Todo trabalhador, ao ser empregado, precisa ser contabilizado separadamente como um indivíduo com seu próprio custo de subsistência a ser conquistado. O fato de que as pessoas convivem com outros trabalhadores pode, no entanto, significar que esse "tempo de trabalho necessário" deve ser considerado, por produzir uma fração, em vez do todo, do custo de subsistência de qualquer indivíduo ou, em outras palavras, que o conceito de "salário-família" é redundante na maioria das circunstâncias. Uma série de outros fatores também interveio no sentido de dificultar a identificação de uma simples correspondência entre o que uma pessoa ganha e quanto custa sobreviver, pelo menos em situações em que ela coabita ou é responsável por dependentes econômicos. Esses fatores complicadores incluem transferências sociais na forma de pensões, benefícios sociais ou créditos fiscais, transferências intergeracionais no seio das famílias, remessas de emigrantes que trabalham no exterior e outras formas de subsídio para alguns (ou pressões sobre os recursos de outros). Apesar dessas dificuldades reais de cálculo, é possível, no entanto, analisar o rendimento de qualquer indivíduo em qualquer domicílio e produzir certa estimativa de como é gerado.

No caso do "trabalho livre" na internet, é provável que uma série de fontes diferentes de rendimento possa estar envolvida. Parte desse trabalho pode ser realizada por pessoas que são economicamente dependentes de seus pais, alguns por pessoas sustentadas por pensões ou que recebem alguma outra forma de benefício social, alguns podem ser feitos por pessoas com salários regulares de trabalhos que os deixam com tempo livre suficiente para blogar, navegar na net ou escrever verbetes da Wikipédia. Alguns podem ser feitos por pessoas (tais como jornalistas independentes, 
consultores ou acadêmicos) cujos empregos as obrigam a se ocuparem com autopromoção. E outros podem estar sendo sustentados por rendas de aluguel [rent], jogos, lucros provenientes do comércio, do crime ou de outras atividades. O que está claro, porém, é que elas não poderiam exercer tal atividade não remunerada sem algum tipo de subsídio advindo de algum lugar. Caso contrário, como elas iriam comer? Ao falhar na organização no local da produção, elas entregam a sua mais forte arma: o poder de retirar o seu trabalho no local onde atingem diretamente o capital.

\section{CONCLUSÃO}

Vivemos em uma sociedade onde o capital está altamente concentrado, com a maioria da produção de mercadorias sendo realizada por empresas cujos destinos são, em grande parte, moldados por investidores financeiros. As mercadorias que produzem, materiais ou imateriais, nos são disponibilizadas em um mercado global, entregues através de complexas cadeias de valor, em cuja operação nosso trabalho não remunerado como consumidores é cada vez mais envolvido. Tecnologias da informação e comunicação têm afetado tanto a divisão espacial e temporal do trabalho que, para muitos de nós, as fronteiras entre trabalho e vida privada formam um emaranhado confuso e poucas relações não são mediadas pela tecnologia. Em tal situação, não seriam os tipos de distinções feitas neste ensaio algo minuciosamente ridículo? Será que não deveríamos apenas aceitar que todos nós somos, de uma forma ou outra, parte de uma enorme força de trabalho indiferenciada, produzindo valor indiferenciado para um capital indiferenciado?

Argumento que não. O capitalismo é uma relação social na qual os trabalhadores desempenham papéis específicos em relação à produção específica de mercadorias. Essa relação depende, fundamentalmente, do consentimento dos trabalhadores. Se não pudermos entender essa relação em sua especificidade, não podemos identificar os pontos críticos nos processos de produção e distribuição nos quais a ação dos trabalhadores pode ser implementada com algum resultado. E, se não pudermos identificá-los, os trabalhadores não podem entender seus poderes de consentir, ou recusar o acordo específico que é oferecido a eles. Isso os impede de renegociar ativamente os termos do acordo - única opção para melhorar sua situação. Sem esse conhecimento, também não podemos ver que grupos de trabalhadores têm interesses em comum, como esses interesses comuns podem se tornar mutuamente visíveis, ou como seu trabalho pode ser interligado.

Cada uma das diferentes formas de trabalho não remunerado descritas acima tem um impacto sobre o trabalho remunerado, abrindo a potencialidade de tensões e fissuras no seio da classe trabalhadora. Estagiários que trabalham de graça, para se tornarem empregáveis, corroem o poder de barganha dos trabalhadores remunerados nos mesmos papéis. Realizar um trabalho de consumo não remunerado afeta os trabalhadores do serviço, ao reduzir os níveis gerais de emprego e ao intensificar o trabalho através da introdução de novas formas de padronização e taylorização, levando à deterioração das condições de trabalho. Escrever verbetes da Wikipédia, "blogar" ou postar vídeos ou fotografias on-line sem remuneração ameaçam a subsistência de jornalistas, pesquisadores e outros trabalhadores criativos que não têm a subvenção de um salário acadêmico, ou outra fonte, e dependem de seu trabalho criativo para gerar um rendimento. Em muitos casos, as mesmas pessoas ocupam vários desses papéis remunerados e não remunerados em diferentes âmbitos. Ainda mais comumente, membros diferentes da mesma família podem estar fazendo isso. Considerar trabalhadores não remunerados como furagreves que estão minando os trabalhadores pagos é, certamente, simplista demais, ignorando os imperativos que impulsionam esses comportamentos e a realidade mais ampla de que a exploração ocorre para todos eles, embora de formas diferentes. Mas uma análise que iguale uma exploração comum a um papel idêntico na geração de mais- 
valia, e que coloque todas essas posições separadas em uma identidade coletiva comum, comouma "multidão”, faz com que seja impossível identificar o local da produção: o ponto em que os trabalhadores têm o poder para desafiar o capital: o centro do nó.

Embora possa ser tedioso desvendar as complexidades das cadeias globais de valor e posicionar nossos processos de trabalho em relação a eles, isso me parece ser uma tarefa absolutamente necessária se quisermos saber como esse sistema pode ser alterado, como agir coletivamente para mudá-lo e que alternativas a ele podemos começar a imaginar.

Recebido para publicação em 21 de junho de 2013 Aceito em 06 de agosto de 2013

\section{REFERÊNCIAS}

ANDREJEVIC, M. Exploiting youtube: contradictions of user-generated labour. In: SNICKERS, P.; VONDERAU, P. (Ed.) The youtube reader. Stockholm: National Library of Sweden, 2009.

ARVIDSSON, A.; COLLEONI, E. Value in informational capitalism and on the internet, The Information Society, [S.1.], v.28, n.3, p.135-150, 2012.

BANKS, J.; HUMPHREYS, S. The labor of user co-creators. Convergence: The International Journal of Research, v. 14, n. 4, p. 401-418, 2008.

ENGELS, F. On Marx's Capital. Moscow: Progress Publishers, 1956 [1877]..

FUCHS, C. Labor in informational capitalism and on the internet. The Information Society, n.26, p.179-196, 2010.

With or without Marx? With or without capitalism? A rejoinder to Adam Arvidsson and Eleanor Colleoni. TripleC: Communication, Capitalism \& Critique, [S.l.], v. 10, n. 2, p. 633-645, 2012.

Dallas Smythe today - the audience commodity, the digital labour debate, marxist political economy and critical theory. Prolegomena to a digital labour theory of value. Triple C: Communication, Capitalism \& Critique, [S.l.], v. 10, n. 2, p. 692-740, 2012.

HARDT, M.; NEGRI., A. Multitude: war and democracy in the age of empire. New York: Penguin, 2004.

HEARN, A. Structuring feeling: Web 2.0, online ranking and rating, and the digital "reputation "economy". Ephemera: Theory \& Politics in Organization, v. 10, n. 3/ 4, p. 421-438, 2010.

HESMONDHALGH, D. User-generated content, free labour and the cultural industries. Ephemera: Theory \& Politics in Organization, v. 10, n. 3/4, p. 267-284, 2011.

HOLTS, K. Towards a taxonomy of virtual work. Hertfordshire: Hertfordshire Business School University Working Paper series, 2013.

HUWS, U. Domestic technology: liberator or enslaver? Scarlet Women, [S.1.], n. 14, 1982.
. Material World: the myth of the weightless economy. Socialist Register, [S.1.], n. 35, p. 29-56, 1999.

The Making of a cybertariat: virtual work in a real world. New York: Monthly Review Press, 2003.

The restructuring of global value chains and the creation of a cybertariat. In: MAY, C. (Ed.). Global corporate power: (re)integrating companies into international political economy Lynne Rienner Publishers, 2006. p. 65-84, (International Political Economy Yearbook v. 15),

. The emergence of EMERGENCE: the challenge of designing research on the new international division of labour. Work Organisation, Labour and Globalisation, London, v.1, n. 2, p. 20-35, 2007.

Expression and expropriation: the dialectics of autonomy and control in creative labour, Ephemera: Theory \& Politics in Organization, v. 10, n. 3/4, 2010.

Crisis as capitalist opportunity: the new accumulation through public service commodification. Socialist Register, [S.1.], n. 35, p. 64-84, 2012.

The reproduction of difference: gender and the global division of labour. Work Organisation, Labour and Globalisation, London, v. 6, n. 1, p.1-10, 2012.

KITTUR et al. 'The Future of Crowd Work', 2013. Disponível em: http://hci.stanford.edu/publications/2013/ CrowdWork/futureofcrowdwork-cscw2013.pdf. Acesso em: 18 mar. 2013.

KÜCKLICH, J. Precarious playbour: modders and the digital games industry. The Fibreculture Journal, [S.l.], n. 5,2005 .

MARX, K. Grundrisse. 1857. Disponível em: http:// www.marxists.org/archive/marx/works/ 1857/grundrisse/ ch03.htm. Acesso em: 25 jan. 2013.

Capital. Capítulo 1. 1867. Disponível em: http:// WWW. marxists.org/archive/marx/works/1867-c1/ commodity.htm. Acesso: 21 jan. 2013.

. Teorias da mais-valia. Capítulo 4.1863. Disponível em: http://www.marxists.org/ archive/marx/works/ 1863/theories-surplus-value/ch04.htm. Acesso em: 21 jan. 2013.

Economic Manuscripts, Chapter 4. 1861-1864a. Disponível em: http://www. marxists.org

Economic Manuscripts, Chapter 2. 1861-1864b. Disponível em: http://www. marxists.org

German Ideology, 'Division of Labour and Forms of Property - Tribal, Ancient, Feudal'. Part 1. 1845, Disponível em: http://www.marxists.org/archive/marx/works/ 1845/ german-ideology/ch01a.htm\#5a3. Acesso em: 01 fev. 2012.

MORINI, C.; FUMAGALLI, A. Life put to work: towards a life theory of value. Ephemera: Theory \& Politics in Organization, v. 10, n. 3/4, p. 234-252, 2010.

PERLIN, R. Intern Nation: how to earn nothing and learn little in the Brave New Economy. London: Verso, 2011.

PRAHALAD, C.K; RAMASWAMY, V. Co-opting customer competence. Harvard Business Review, v. 9, jan./feb. 2000.

ROSS, A. On the digital labour question. In: SCHOLZ, T. (Ed.) The internet as playground and factory. New York: Routledge, 2012.

In search of the lost paycheck. In: T SCHOLZ, T. (Ed.) The internet as playground and factory. New York: Routledge, 2012.

SCHOLZ, T. The internet as playground and factory. New York: Routledge, 2012. 
SMYTHE, D. W. Communications: blindspot of western Marxism. Canadian Journal of Political and Social Theory, [S.l.], v. 1, n. 3, p. 1-27, 1977.

On the audience commodity and its work. In: DUNCAN, M. G.; KELLNER, D.M. (Ed.) Media and cultural studies. Malden, MA: Blackwell, 1981.

STANDING, G. Precariat: the new dangerous class. London; New York: Bloomsbury, 2011.
TERRANOVA, T. Free labor: producing culture for the digital economy. Social Text, New York, v. 18, n. 2, p. 33$58,2000$.

Free labor. In: SCHOLZ T (Ed.). The Internet as Playground and Factory. New York: Routledge, 2012.

WEINBAUM, B.; BRIDGES, A. The other side of the paycheck: monopoly capital and the structure of consumption. Monthly Review, San Diego, v. 28, n. 3, 1976. 


\section{LIVING, LABOUR AND VALUE IN THE XXI ${ }^{\text {ST }}$ CENTURY: unpicking the knot}

\section{Ursula Elin Huws}

It is often argued that Marx's labour theory of value no longer applies in the contemporary world in which increasing proportions of the population are involved in "immaterial" or "digital" labour. This article contends that the theory is still relevant, but that in order to understand how it can be applied both to immaterial labour and to labour more generally, it is necessary to examine critically the three key components of the theory: the particular nature of any given form of labour, the value that is created by that labour, and the worker's means of subsistence. Such an analysis enables us not only to distinguish between "necessary labour time" and surplus value but also to identify the point of production. In a world in which new activities are constantly being brought within the sphere of capitalist social relations and new commodities are being produced, it is important to identify these points of production and the workers who are directly engaged in the production of surplus value because it is these workers who have the potential, by withdrawing their consent, to organise effectively in the common interests of the global working class.

KEY wORDS: labour theory of value, immaterial labour, commodification, monetisation of the Internet, labour, digital labour, productive and unproductive labour.

\section{VIE, TRAVAIL ET VALEUR AU 21e SIÈCLE: défaisant le noeud}

\section{Ursula Elin Huws}

La théorie de la valeur-travail de Marx est souvent considérée comme une théorie ne s'appliquant plus au monde contemporain où une partie de plus en plus grande de la population est impliquée dans un travail "immatériel" ou un travail "numérique". On démontre dans cet article qu'elle est toujours d'actualité mais que pour comprendre la manière dont elle peut être appliquée au travail immatériel et au travail en général, il est nécessaire de faire une analyse critique des trois principaux éléments de cette théorie : la nature particulière de toute forme de travail, la valeur engendrée par ce travail et les moyens de subsistance du travailleur. Cette analyse nous permet non seulement de faire la distinction entre le "temps de travail nécessaire" et la plus-value mais aussi d'identifier le lieu de production. Dans un monde où de nouvelles activités sont continuellement introduites dans la sphère des relations sociales capitalistes et que de nouveaux produits sont fabriqués, il est important d'identifier ces lieux de production ainsi que les travailleurs directement impliqués dans la production de la plus-value car ce sont ces travailleurs qui sont capables de s'organiser de manière efficace pour défendre les intérêts de la classe ouvrière mondiale.

Mots-CLÉs: Théorie de la valeur-travail. Travail immatériel. Marchandisation. Monétarisation d’internet. Travail. Travail numérique. Travail productif et improductif.

Ursula Elin Huws - Doutora em Sociologia pela London Metropolitan University. Professora do Departamento de Business da Universidade de Hertfordshire. Integra o Núcleo de Pesquisa Labour and Globalisation, desenvolvendo pesquisas na área de trabalho virtual. Suas mais recentes publicações, são: Socialist register, 2012; Crisis as capitalist opportunity: new accumulation through public service commodification, 2011; Expression and expropriation: the dialectics of autonomy and control in creative labour. Ephemera: Theory \& Politics in Organization v. 10, n. 3/4. 2010. 